\title{
Presence of Ochratoxin in a Green Coffee Beans Processed Naturally by Smallholder Farmers in Jember
}

\author{
Rosavani $\mathrm{MA}^{1}$ and Harada $\mathrm{H}^{2 *}$ \\ ${ }^{1}$ Faculty of Agricultural Technology, Indonesia \\ ${ }^{2}$ Faculty of Life and Environmental Science, Japan \\ *Corresponding author: Harada H, Faculty of Life and Environmental Science, Japan
}

Submission: February 13, 2019; Published: February 22, 2019

\begin{abstract}
Moulds growth and contaminated green coffee beans, produced mycotoxins as secondary metabolites such as Ochratoxin A. Ochratoxin A have been reported carcinogen in human health. The aim of this research was determined the occurrence of Ochratoxin A in green coffee beans using C18 SPE cartridges as alternative clean-up method. Samples were collected from Argo puro mountain areas, Jember Indonesia during the coffee year. Samples were prepared with extraction, clean-up, separation, and quantification. The parameter of OTA was determined by HPLC-FL Detector fitted with C18 HPLC column. The result shown 9 of 10 samples were detected OTA with the highest concentration was $0.4319 \mathrm{ppm}$ and the lowest concentration was $0.0146 \mathrm{ppm}$.
\end{abstract}

Keywords: Jember green coffee beans; Ochratoxin A; C18 SPE Cartridges

\section{Introduction}

Mycotoxins are contamination toxin produced by filamentous fungi as second metabolite produced. OTA has been reported in coffee beans [1-3]. International Agency for Research of Cancer has classified OTA in group 2B as a possible human carcinogen [4]. Clean-up is the step called for enrichment OTA, usually used liquidliquid and solid-solid extraction [5]. Immunoaffinity SPE cartridges are high cost, for the main reason more economic alternatives are required. C18 SPE cartridges known as recommended applications for aflatoxins determination. The aims of this study were determined the amount of Ochratoxin A in green coffee beans produced by smallholder farmers in Jember using C18 SPE cartridges as the economic clean-up separation.

\section{Material and Methods}

\section{Sample collection}

A total of 10 green coffee beans collected during coffee year.

\section{Sample preparation}

$100 \mathrm{mg}$ of chloroform and $12.5 \mathrm{~mL}$ of phosphoric acid $(0.1 \mathrm{M})$ added into Erlenmeyer flask with $10 \mathrm{~g}$ of ground coffee. The mixture was stirred and filtered. The filtrate was transfer into $500 \mathrm{~mL}$ separatory funnel, $50 \mathrm{~mL}$ of the lower layer transferred to roundbottom flask and evaporated to dryness. The residue was dissolved in $5 \mathrm{~mL}$ of hexane and $5 \mathrm{~mL}$ of methanol/ water mixture $(1: 1, \mathrm{v} / \mathrm{v})$, filtered and the filtrate were transferred into $50 \mathrm{~mL}$ separatory funnel. The lower layer was collected into $25 \mathrm{~mL}$ Erlenmeyer flask, and the upper phase extracted twice with $5 \mathrm{~mL}$ methanol/ water mixture $(1: 1, v / v)$ to rinse the round bottom flask containing the residue.

\section{Solid phase extraction (SPE)}

The C18 SPE (Inert Sep VRA-2 6mL) conditioned with $5 \mathrm{~mL}$ of methanol and $5 \mathrm{~mL}$ of methanol/water mixture $(1: 1, \mathrm{v} / \mathrm{v}) .5 \mathrm{~mL}$ sample were loaded into C18 cartridges. The cartridges washed with $5 \mathrm{~mL}$ methanol/water mixture $(3: 1, \mathrm{v} / \mathrm{v})$. OTA was eluted from the cartridges with $10 \mathrm{~mL}$ of methanol/formic acid mixture (98:2, $\mathrm{v} / \mathrm{v}$ ). The solution evaporated under nitrogen stream for $2 \mathrm{~min}, 45$ ${ }^{\circ} \mathrm{C}$. The solution was added with Trifluoro Acetic Acid $0.1 \mathrm{~mL}$ and stirred about $15 \mathrm{~min}$, added with $0.9 \mathrm{~mL}$ of Acetonitrile/water mixture $(1: 9, \mathrm{v} / \mathrm{v})$ and injected into HPLC-FLD.

\section{HPLC injection}

HPLC fitted with C18 HPLC column (Inert Sustain swift, C18/ $50 \mathrm{~m}, 4.6 \times 250 \mathrm{~mm}$ ). Mobile phase solution was Acetonitrile: Glacial acetic acid: Distilled water (5:1:4, v/v). Flow rate was 0.700, temperature control $45{ }^{\circ} \mathrm{C}$, Ex 333nm, and Em 450nm. Samples were loaded $20 \mu \mathrm{L}$ with micro insert. 


\section{Result and Discussion}

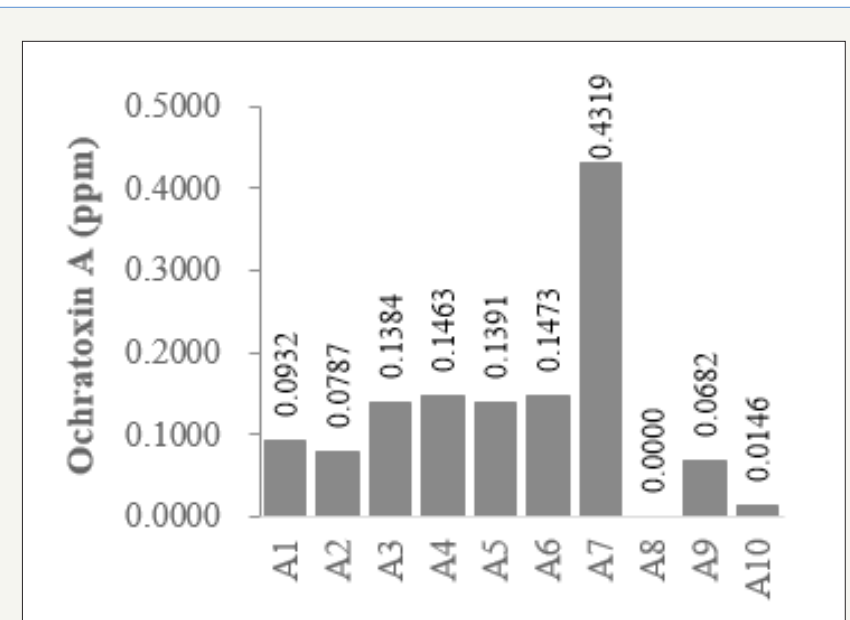

Figure 1: Occurrence of ochratoxin a in green coffee beans collected in Jember.

The results of the Ochratoxin A analysis of 10 samples were shown in Figure 1. A7 was the highest Ochratoxin A with concentration of $0.4319 \mathrm{ppm}$. And A10 was the lowest Ochratoxin A with concentration of $0.0146 \mathrm{ppm}$. A8 was not detected as Ochratoxin A contamination in coffee sample. The difference of the concentration shown in Figure 1 caused by many factors such different location of the coffee growth and the process after harvesting the coffee beans. The lack of clear difference in the incidence and concentration of mycotoxins in agricultural commodities is affected by many factors, such as environmental and geographic location where crops are grown. In addition, harvest and the storage conditions may influence the mycotoxin production [6,7]. C18 column as SPE clean-up could be determined OTA as immunoaffinity column. This alternative could reduce high cost because of high demand of immunoaffinity column. C18 SPE is more efficient and more precise than immunoaffinity cartridges. C18 much lower than the price of immunoaffinity cartridges [4].

\section{Conclusion}

The determination of ochratoxin A with HPLC-FL Detector method fitted with C18 SPE (Solid Phase Extraction) cartridges as clean-up method give best result of 10 ground coffee samples. The amount of difference Ochratoxin A caused by many factors. It depends on the location of the coffee growth, the moulds that contaminated, climate, and quality of the process used by farmer.

\section{References}

1. Kuntawee S, Akarapisan A (2015) Isolation and identification of aspergillus species producing ochratoxin a in arabica coffee beans. International Journal of Agricultural Technology 11(5): 1235-1242.

2. Abdalall A, Amira HA, Talib A, Ebtisam A (2014) Aflatoxin and ochratoxin production in ground coffee during storage. Canadian Journal of Pure and Applied Sciences 8(2): 2825-2836.

3. Oliveira G, Silva DM, Pereira RGFA, Paiva LC, Prado G, et al. (2013) Effect of different roasting levels and practice sizes on ochratoxin a concentration in coffee beans. Journal of Food Control 34: 651-656.

4. Ocnaru E, Doni BM, Cheregi M, Mihaela CC, Maria LJ, et al. (2014) A robust method for determination of ochratoxin a in wine samples by SPE and HPLC-FLD. Revista de Chimie-Bucharest 65(5): 516-520.

5. FAO (2004) Good hygiene practice along the coffee chain: overview of analytical methods for ochratoxin a. FAO food and Nutritional Organization 81: 1-8.

6. Leah MM, Koskei R, Mburu M (2017) Moulds and ochratoxin an associated with green coffee (coffea arabica) beans processed by dry and wet methods in nyeri country. IOSR Journal of Environmental Science, Toxicology, and Food Technology 11(6): 66-72.

7. Cappozzo J, Jackson L, Jung LH, Zhou W, Taher FA, et al. (2017) Occurrence of ochratoxin a in infant foods in the united states. J Food Prot 80(2): 251-256.
Creative Commons Attribution 4.0 International License

For possible submissions Click Here

\section{Submit Article}

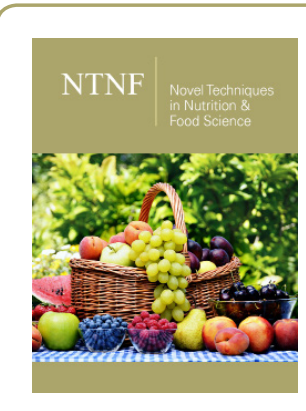

Novel Techniques in Nutrition and Food Science

\section{Benefits of Publishing with us}

- High-level peer review and editorial services

- Freely accessible online immediately upon publication

- Authors retain the copyright to their work

- Licensing it under a Creative Commons license

- Visibility through different online platforms 